\title{
Autoimmune Ascites Responding to Mycophenolate Mofetil: A Case Report
}

\author{
Douglas A. Simonetto ${ }^{a}$ Hala Fatima ${ }^{b}$ Folkert Zijlstrac \\ Michael K. Zijlstra ${ }^{d}$ \\ aDepartment of Gastroenterology, Mayo Clinic Rochester, Rochester, MN, USA; \\ ${ }^{b}$ Department of Gastroenterology-Hepatology, Indiana University Health University \\ Hospital, Indianapolis, IN, USA; 'Department of Gastroenterology, Lutheran Hospital, \\ Fort Wayne, IN, USA; ${ }^{d}$ Chicago College of Osteopathic Medicine, Downers Grove, IL, USA
}

\section{Keywords}

Ascites · Mycophenolate mofetil · Autoimmune disease

\begin{abstract}
Ascites is an abnormal accumulation of fluid within the peritoneal cavity. The most common cause of ascites in the United States population is portal hypertension secondary to cirrhosis, accounting for about $80 \%$ of the cases. Other etiologies include malignancy, heart failure, tuberculosis, and pancreatic disease. After an extensive literature review, it is to our best knowledge that there have been no cases reported on autoimmune ascites. We present an interesting case of ascites in a 67-year-old Caucasian male with symptoms of recurrent abdominal distention and significant weight gain, refractory to standard therapies. An extensive 3-year long workup was only significant for serum-ascites albumin gradient $>1.1 \mathrm{~g} / \mathrm{dL}$, ascitic fluid protein of $3.0 \mathrm{~g} / \mathrm{dL}$, and peritoneal biopsies showing minor inflammatory changes. Both common and rare causes of ascites were ruled out. Empiric treatment with mycophenolate mofetil (CellCept) resulted in resolution of symptoms with no need for a repeat paracentesis for $>2$ years, suggesting the diagnosis of autoimmune ascites.
\end{abstract}




\section{Case Reports in Gastroenterology}

\begin{tabular}{l|l}
\hline Case Rep Gastroenterol 2018;12:207-216 \\
\hline DOI: 10.1159/000488975 & $\begin{array}{l}\text { (c 2018 The Author(s). Published by S. Karger AG, Basel } \\
\text { www.karger.com/crg }\end{array}$
\end{tabular}

Simonetto et al.: Autoimmune Ascites Responding to Mycophenolate Mofetil: A Case Report

\section{Introduction}

Ascites is defined as a pathologic accumulation of fluid within the peritoneal cavity. Broadly, ascites can be categorized into 2 separate pathophysiology mechanisms $[1,2]$. The first is portal hypertension, which causes increased hydrostatic pressure in the vasculature, forcing fluid out of the blood vessels and into the peritoneal cavity [2]. The second major mechanism is nonportal hypertension mediated; it is caused by the loss of proteins such as albumin, leading to a decreased oncotic pressure within the plasma and forcing fluid into the peritoneum [2]. The most common etiology of ascites in the United States is portal hypertension, secondary to (1) cirrhosis and (2) heart failure. Other "nonportal hypertension" causes include malignancy, TB, and nephrotic syndromes. Autoimmune ascites is an extremely rare disease with no current literature published to date. Some more prevalent immune-mediated causes of ascites include systemic lupus erythematosus (SLE), rheumatoid arthritis, and polyneuropathy, organomegaly, endocrinopathy, monoclonal protein, skin changes (POEMS) syndrome, all of which are also rare [3-5].

We describe the case of a 67-year-old Caucasian male with autoimmune ascites. His peritoneal biopsies demonstrated monocyte infiltration, and he responded favorably to immunosuppressive therapy. It is our hope to share this unique presentation and begin to better understand this rare condition.

\section{Case Presentation}

A 67-year-old Caucasian male presented to his local GI clinic in October 2013 with a 1.5month history of progressively increasing abdominal distention and fullness.

Other symptoms included nausea and fullness with meals, as well as early satiety.

An abdominal computed tomography (CT) scan from his primary care physician visit 1week before demonstrated severe ascites. He denied any history of liver or cardiac problems, transfusions, or family history of liver or cardiac disease. His past medical history includes hypertension controlled with metoprolol $100 \mathrm{mg}$ and hydrochlorothiazide $25 \mathrm{mg}$, anxiety/depression controlled with lorazepam $0.5 \mathrm{mg}$ and venlafaxine $75 \mathrm{mg}$, hypercholesterolemia controlled with aspirin $81 \mathrm{mg}$ and simvastatin $40 \mathrm{mg}$, and obstructive sleep apnea with current use of continuous positive airway pressure nightly.

The patient noted a drinking history of 12-24 ounces of beer per day for 4-5 years, with the last drink over 30 years ago.

During the initial visit, the patient was in no distress and had no scleral icterus, jaundice, or jugular venous distention. His lungs were clear to auscultation bilaterally, heart examination revealed a normal rate without murmurs, rubs, or gallops. No lower-extremity edema was noted. The abdomen was distended, bowel sounds were present in all 4 quadrants, and no hepatosplenomegaly was appreciated.

The patient was started on furosemide $40 \mathrm{mg}$, spironolactone $50 \mathrm{mg}$, and hydrochlorothiazide $25 \mathrm{mg}$ daily. Additionally, he was instructed to adhere to a low sodium $(<2 \mathrm{~g} /$ day $)$ and a low fluid diet ( $<2 \mathrm{~L} /$ day).

Initial laboratory results are shown in Table 1 and Table 2. Electrocardiogram revealed normal sinus rhythm with no abnormal findings, and chest X-ray showed no cardiopulmonary 


\section{Case Reports in Gastroenterology}

Case Rep Gastroenterol 2018;12:207-216

DOI: $10.1159 / 000488975$

(c) 2018 The Author(s). Published by S. Karger AG, Base www.karger.com/crg

Simonetto et al.: Autoimmune Ascites Responding to Mycophenolate Mofetil: A Case Report

abnormalities. CT of the abdomen showed moderate-severe ascites without evidence of nodularity of the liver, splenomegaly, or other signs of portal hypertension. There was no thickening or opacification of the mesentery, omentum, or peritoneum. No enlarged lymph nodes were visualized. Ultrasound-guided paracentesis was performed with drainage of $10 \mathrm{~L}$ of clear, yellow, ascitic fluid. Peritoneal-fluid analysis demonstrated a transudative ascites with a serum-ascites albumin gradient calculated to be $1.9 \mathrm{~g} / \mathrm{dL}$. The fluid contained $87 \%$ lymphocytes and an elevated total protein of $3.0 \mathrm{~g} / \mathrm{dL}$. The specimen showed a mixture of lymphocytes, mesothelial cells, and scattered inflammatory cells. Cells that displayed vacuolar changes and focal signet ring patterns were present, likely representing degenerative changes. No signs of malignant cells, fungi, or acid-fast bacilli were observed. CT-guided biopsy of the liver exhibited nonspecific reactive hepatitis with a slightly increased lymphocyte count; no interface activity, sinusoidal dilation, congestion, or fibrotic changes were noted (Fig. 1). Hepatic Doppler ultrasonography revealed patency of the portal vein with a normal hepatopetal flow. During this 6-month workup, the patient underwent therapeutic paracentesis 3 additional times, with approximately $8 \mathrm{~L}$ of fluid drained each time, despite increasing doses of diuretics. Due to uncertainty of the cause of the ascites, the patient was referred to a tertiary center for further assessment.

In January 2014, the patient began his workup at a larger tertiary center. Repeat workup revealed similar results as the initial testing. Ultrasound with Doppler was ordered to evaluate the vasculature. It demonstrated patency of the hepatic vessels. Additionally, no signs of underlying cirrhosis were noted. There was concern for a cardiac cause due to his high ascitic protein level $(3.0 \mathrm{~g} / \mathrm{dL})$. Echocardiogram results were within normal limits; right heart catheterization revealed normal pressures without evidence of pulmonary hypertension. Cardiac output and filling pressures were within normal limits. After ruling out cirrhosis and right heart failure, hematology was consulted. Serum plasma electrophoresis and bone marrow biopsy were performed due to concern for plasma cell dyscrasias. All returned negative results. Vascular endothelial growth factor (VEGF) was the only laboratory value that was found to be slightly elevated to $105 \mathrm{pg} / \mathrm{mL}$ (upper limit of normal $80 \mathrm{pg} / \mathrm{mL}$ ). He was initiated on pentoxifylline (PTX) $400 \mathrm{mg}$ t.i.d. in an attempt to decrease the inflammatory-mediated recurrent ascites. At the following clinic visit, the patient returned with the same complaints and no relief of symptoms. He was still having recurrent ascites requiring paracentesis every 2 months. At this point, PTX and lasix were discontinued. The patient's spironolactone was increased to $100 \mathrm{mg}$, and he was referred to a larger tertiary center for further investigation.

In May 2015, the patient was evaluated at an additional tertiary center. Repeat workup was again unrevealing. Ancillary testing of NT-proBNP was within normal limits $(<25 \mathrm{pg} / \mathrm{mL})$. Cardiac etiology was ruled out. The only other significant laboratory finding included an elevated C-reactive protein (CRP) of $16.3 \mathrm{mg} / \mathrm{L}$. A hepatic venogram revealed a normal hepatic venous pressure gradient (HVPG) of $3 \mathrm{~mm} \mathrm{Hg}$ (free hepatic vein pressure of $11 \mathrm{mmHg}$ and wedge pressure of $14 \mathrm{~mm} \mathrm{Hg}$ ). Due to an extensive workup without an identifiable etiology, an exploratory laparoscopy with peritoneal biopsies and cultures were performed. The findings revealed no evidence of underlying malignancy or bacterial or fungal infections. Fibroadipose tissue associated with benign lymphoid tissue was found in peritoneal and omental biopsies. After analyzing the 3-year workup without definitive diagnosis, it was hypothesized that an autoimmune reaction was responsible for driving the fluid into the abdomen. 


\section{Case Reports in Gastroenterology}

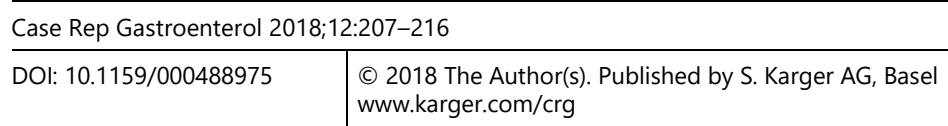
www.karger.com/crg

Simonetto et al.: Autoimmune Ascites Responding to Mycophenolate Mofetil: A Case Report

Prednisone taper was discussed but declined by the patient due to an adverse reaction to corticosteroids in the past. Mycophenolate mofetil monotherapy was initiated at a starting oral dose of $1 \mathrm{~g}$ b.i.d.

The patient has recently been back at his local GI clinic in November 2017 and was feeling well. He was responding to a lower dose of mycophenolate mofetil $500 \mathrm{mg}$ b.i.d., along with spironolactone $100 \mathrm{mg}$ daily and adherence to a low-sodium diet. The patient's last paracentesis was 2 years ago.

\section{Discussion}

This is a case of a 67-year-old male with recurrent abdominal ascites. Extensive diagnostic evaluation allowed us to exclude infection, malignancy, and granulomatous and metabolic disease processes. With the significant findings of serum-ascites albumin gradient $>1.1$, portal hypertension from liver disease was initially suspected; however, unremarkable abdominal imaging and liver biopsies pointed away from this hypothesis. This was later confirmed with a normal HVPG level of $3.0 \mathrm{~mm} \mathrm{Hg}$ (normal range 1-5). Portal hypertension is identified by a

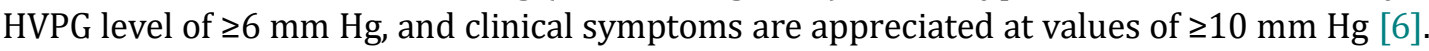
With portal hypertension ruled out and an elevated fluid protein of $3.0 \mathrm{~g} / \mathrm{dL}$, a cardiac etiology was next considered. Chest X-ray and electrocardiogram suggested no cardiac pathology. Echocardiography and right heart catheterization were performed, both yielding normal findings. Ascitic fluid culture and biopsies ruled out bacterial and fungal infections, as well as malignancy. With negative antinuclear antibody, rheumatoid factor, c-ANCA, and p-ANCA, we were able to rule out extra-articular involvement from rheumatoid arthritis and SLE. After this negative comprehensive workup, additional rare causes of ascites were explored.

VEGF was found to be slightly elevated at $105 \mathrm{mg} / \mathrm{dL}$. This raised concern for an autoinflammatory disease process causing endothelial disruption. VEGF is a signal protein produced by cells that stimulates angiogenesis and increases vascular permeability [7]. Overexpression of VEGF can be associated with cancer and vascular diseases [7]. One such disease is POEMS syndrome. POEMS syndrome is defined by the existence of a monoclonal plasma cell disorder, peripheral neuropathy, and one or more of the subsequent conditions: increased levels of VEGF, edema/ascites, organomegaly, skin changes, papilledema, osteosclerotic myeloma, Castleman disease (angiofollicular lymph node hyperplasia), and an endocrinopathy (excluding diabetes mellitus and hypothyroidism) [8]. Table 3 includes the mandatory, major, and minor criteria for the diagnosis of POEMS syndrome. The cause of POEMS syndrome remains unclear; however, sustained synthesis of proinflammatory molecules, such as VEGF, appears to be a major feature of this disorder [8].

The diagnosis of POEMS syndrome is confirmed when both of the mandatory criteria, 1 of the 3 major criteria, and 1 of the 6 minor criteria are present. After bone marrow biopsies had shown no abnormalities, POEMS syndrome was excluded. Of note, the VEGF levels tend to be 2 times higher than the upper limit of normal (upper limit of normal $80 \mathrm{pg} / \mathrm{mL}$ ) in patients with POEMS [8]. Due to the patients modest elevation (105 pg/mL), it was hypothesized that an inflammatory process was a cause for the ascites. The patient was next started on PTX 400 mg t.i.d. 
PTX is a methylxanthine derivative that inhibits phosphodiesterase, causing vasodilation of peripheral arteries. It can be used in the treatment of peripheral vascular disease. The goal of prescribing the patient PTX was to inhibit what was hypothesized to be an inflammatorymediated ascites. It is understood that PTX has the ability to inhibit the proliferation of inflammatory cytokines such as TNF-alpha and IL-6 $[9,10]$. It is known that TNF-alpha is a dose- and time-dependent inducer of VEGF expression [11]. More specifically, by inhibiting the VEGFstimulating factor, TNF-alpha, we could decrease the VEGF. We hypothesized that by decreasing the VEGF, vascular permeability would decrease, and the patient's ascites would resolve. After a 6-month trial of PTX, the patient's condition was unchanged, and his VEGF levels remained slightly elevated.

The next step on his evaluation included an exploratory laparotomy. No malignancy or gross abnormality of the peritoneum was observed. Peritoneal and omental biopsies showed fibroadipose tissue associated with benign lymphoid tissue. This, supported by an elevated CRP, led us to hypothesize that the ascites may be autoimmune in nature. Finally, the patient was started on mycophenolate mofetil with an excellent response.

Mycophenolate mofetil is an immunosuppressant agent primarily used to prevent organ transplant rejection. More specifically, it is used in patients receiving allogenic hepatic, cardiac, and renal transplants. Current literature shows an increasing use of this drug as a steroid-sparing treatment in some autoimmune diseases: SLE, vasculitides, and psoriasis among others [12-14]. Mycophenolate mofetil is processed into the active metabolite mycophenolic acid (MPA) [15]. MPA is a reversible inhibitor of inosine monophosphate dehydrogenase [15].

Inosine monophosphate dehydrogenase is the rate-limiting enzyme in de novo synthesis of guanosine nucleotides [15]. Both T- and B-lymphocytes are dependent on the de novo synthesis of purines such as guanosine, while most other cell types can utilize the salvage pathways [16]. Therefore, MPA has a potent cytostatic effect on lymphocytes as compared to other cell types. This mechanism is responsible for the immunosuppressive effects of the drug [16]. To the best our knowledge, there is no literature on the use of mycophenolate mofetil in patients with autoimmune ascites.

In this report, we discuss the extensive workup of recurrent, unexplained ascites in a 67year-old Caucasian male. After common causes of ascites were ruled out, rare etiologies were considered and investigated, including POEMS syndrome. Based on the patient's negative workup, elevated CRP level, and benign lymphoid tissue proliferation on peritoneal biopsies, it was hypothesized that his ascites was due to an autoimmune process. The patient was started on empiric treatment with mycophenolate mofetil and he responded favorably. The goal of this report is to increase awareness of this rare presentation of ascites. Future research is needed to better understand autoimmune ascites.

\section{Statement of Ethics}

The authors have no ethical conflicts to disclose. 


\section{Case Reports in \\ Gastroenterology}

Case Rep Gastroenterol 2018;12:207-216

DOI: $10.1159 / 000488975$

(c) 2018 The Author(s). Published by S. Karger AG, Base www.karger.com/crg

Simonetto et al.: Autoimmune Ascites Responding to Mycophenolate Mofetil: A Case Report

\section{Disclosure Statement}

The authors declare that there are no conflicts of interest to disclose.

\section{References}

1 Runyon BA. Management of adult patients with ascites caused by cirrhosis. Hepatology. 1998 Jan;27(1):26472.

2 Sitaraman SV, Friedman LS. Essentials of gastroenterology. Chichester, West Sussex: Wiley-Blackwell: 2012, pp 232-234.

3 Man BL, Mok CC. Serositis related to systemic lupus erythematosus: prevalence and outcome. Lupus. 2005;14(10):822-6.

4 Szeto MC, Disney B, Perkins P, Wood G. Ascites and other incidental findings revealing undiagnosed systemic rheumatoid arthritis. BMJ Case Rep. 2015 Jun;bcr2014207142.

5 Al-Mayoof O. Al Sughaiyer H, Abuomar W, Khan M: POEMS syndrome: a rare cause of exudative ascites and chronic peripheral neuropathy. BMJ Case Rep. 2017 Jun;bcr-2016-219022.

6 Groszmann RJ, Wongcharatrawee S. The hepatic venous pressure gradient: anything worth doing should be done right. Hepatology. 2004 Feb;39(2):280-2.

7 Dvorak HF, Nagy JA, Feng D, Brown LF, Dvorak AM. Vascular permeability factor/vascular endothelial growth factor and the significance of microvascular hyperpermeability in angiogenesis. Curr Top Microbiol Immunol. 1999;237:97-132.

8 Dispenzieri A. POEMS syndrome: 2017 Update on diagnosis, risk stratification, and management. Am J Hematol. 2017 Aug;92(8):814-29.

9 Hernández E, Correa A, Bucio L, Souza V, Kershenobich D, Gutiérrez-Ruiz MC. Pentoxifylline diminished acetaldehyde-induced collagen production in hepatic stellate cells by decreasing interleukin- 6 expression . Pharmacol Res. 2002 Nov;46(5):435-43.

10 Ramesh G, Reeves WB. TNF- $\alpha$ mediates chemokine and cytokine expression and renal injury in cisplatin nephrotoxicity. J Clin Invest. 2002 Sep;110(6):835-42.

11 Giraudo E, Primo L, Audero E, Gerber HP, Koolwijk P, Soker S et al. Tumor necrosis factor-alpha regulates expression of vascular endothelial growth factor receptor- 2 and of its co-receptor neuropilin-1 in human vascular endothelial cells. J Biol Chem. 1998 Aug;273(34):22128-35.

12 Sahin A. Mycophenolate mofetil in the treatment of systemic lupus erythematosus. Eurasian J Med. 2009 Dec;41(3):180-5.

13 Hiemstra TF, Jones RB, Jayne DR. Treatment of primary systemic vasculitis with the inosine monophosphate dehydrogenase inhibitor mycophenolic acid. Nephron Clin Pract. 2010;116(1):c1-10.

14 Orvis AK, Wesson SK, Breza TS Jr, Church AA, Mitchell CL, Watkins SW. Mycophenolate mofetil in dermatology. J Am Acad Dermatol. 2009 Feb;60(2):183-99.

15 Allison AC. Immunosuppressive drugs: the first 50 years and a glance forward. Immunopharmacology. 2000 May;47(2-3):63-83.

16 Eugui EM, Almquist SJ, Muller CD, Allison AC. Lymphocyte-selective cytostatic and immunosuppressive effects of mycophenolic acid in vitro: role of deoxyguanosine nucleotide depletion. Scand J Immunol. 1991 Feb;33(2):161-73. 


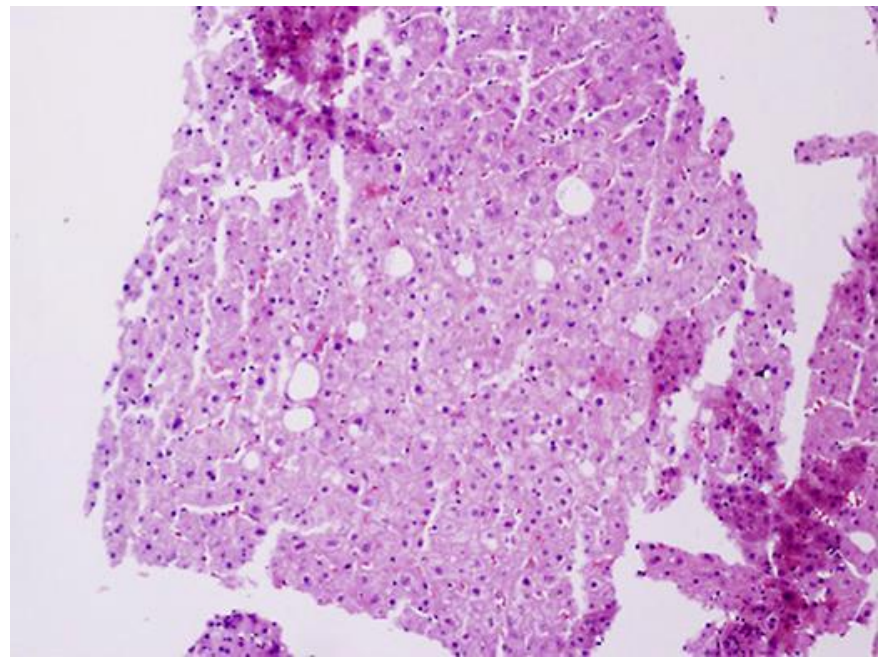

Fig. 1. H\&E Liver biopsy $\times 10$ magnification. Image shows histological slide with H\&E staining from computed-tomography-guided liver biopsy of the patient during initial workup in 2013. The biopsy exhibits nonspecific reactive hepatitis with a slightly increased lymphocyte count; no interface activity, sinusoidal dilation, congestion, or fibrotic changes were noted. 
\begin{tabular}{l|l} 
DOI: $10.1159 / 000488975$ & (c) 2018 The Author(s). Published by S. Karger AG, Basel
\end{tabular} www.karger.com/crg

Simonetto et al.: Autoimmune Ascites Responding to Mycophenolate Mofetil: A Case Report

Table 1. Initial laboratory results

\begin{tabular}{|c|c|c|}
\hline Test name & Result & Reference \\
\hline \multicolumn{3}{|l|}{ Blood } \\
\hline WBC & $12.8 \times 1,000 / \mathrm{uL}$ & $(4.8-10.8)$ \\
\hline Hemoglobin & $15.6 \mathrm{~g} / \mathrm{dL}$ & $(14-18)$ \\
\hline Platelet count & $272 \times 1,000 / u L$ & $(140-440)$ \\
\hline PT & $11.1 \mathrm{~s}$ & $(9.6-12.3)$ \\
\hline INR & 1 & \\
\hline Sodium & $143 \mathrm{mEq} / \mathrm{L}$ & $(137-148)$ \\
\hline Potassium & $4 \mathrm{mEq} / \mathrm{L}$ & $(3.5-5.1)$ \\
\hline Chloride & $103 \mathrm{mEq} / \mathrm{L}$ & $(98-12)$ \\
\hline $\mathrm{CO}_{2}$ & 36 mEq/L & $(20-2)$ \\
\hline Anion gap & $4 \mathrm{mEq} / \mathrm{L}$ & $(5.0-14)$ \\
\hline Glucose & $104 \mathrm{mg} / \mathrm{dL}$ & $(70-99)$ \\
\hline Creatinine & $0.9 \mathrm{mg} / \mathrm{dL}$ & $(0.9-1.3)$ \\
\hline BUN & $18 \mathrm{mg} / \mathrm{dL}$ & $(6.0--20)$ \\
\hline Albumin & $3.9 \mathrm{~g} / \mathrm{dL}$ & $(3.4-4.8)$ \\
\hline Total protein & $6.2 \mathrm{~g} / \mathrm{dL}$ & $(6.4-8.3)$ \\
\hline Total bilirubin & $0.9 \mathrm{mg} / \mathrm{dL}$ & $(0.3-1.2)$ \\
\hline Alkaline phosphatase & $80 \mathrm{U} / \mathrm{L}$ & $(25-100)$ \\
\hline Globulin & 2.3 & $(1.6-4.9)$ \\
\hline AST & $20 \mathrm{U} / \mathrm{L}$ & $(8.0-30)$ \\
\hline ALT & $24 \mathrm{U} / \mathrm{L}$ & $(10.0-50)$ \\
\hline Iron & $72 \mathrm{ug} / \mathrm{dL}$ & $(53-187)$ \\
\hline$\%$ Saturation & $28 \%$ & $(20-55)$ \\
\hline Ferritin & $152 \mathrm{ng} / \mathrm{mL}$ & $(10-322)$ \\
\hline HBsAg & Nonreactive & \\
\hline HA IgM & Nonreactive & \\
\hline HBc IgM & Nonreactive & \\
\hline Hep C Ab & Nonreactive & \\
\hline Antinuclear antibodies titer & Negative & \\
\hline Antimitochondrial antibodies & Negative & \\
\hline Alpha-1-antitrypsin & $148 \mathrm{mg} / \mathrm{dL}$ & $(90-200)$ \\
\hline Ceruloplasmin & $25.2 \mathrm{mg} / \mathrm{dL}$ & $(15-30)$ \\
\hline Alpha-fetoprotein & $1.5 \mathrm{ng} / \mathrm{mL}$ & $(0-8.3)$ \\
\hline Anti-smooth muscle antibody & $6 \mathrm{U}$ & $(0-19)$ \\
\hline Amylase & $41 \mathrm{U} / \mathrm{L}$ & $(20-104)$ \\
\hline Carcinoembryonic antigen & $0.7 \mathrm{ng} / \mathrm{mL}$ & $(0-3.0)$ \\
\hline TSH & $3.317 \mathrm{uIU} / \mathrm{mL}$ & $(0.4-5.3)$ \\
\hline Cancer antigen 19-9 & $4 \mathrm{U} / \mathrm{mL}$ & $(0-35)$ \\
\hline
\end{tabular}

Overview of the patient's laboratory results during initial presentation in 2013. WBC, white blood cell count; PT, prothrombin time; INR, international normalized ratio; BUN, blood urea nitrogen; AST, aspartate aminotransferase; ALT, alanine aminotransferase; HBsAg, hepatitis B virus surface antigen; HA IgM, hepatitis A immunoglobulin M; Hep C Ab, hepatitis C antibody. 


\begin{tabular}{l|l}
\hline Case Rep Gastroenterol 2018;12:207-216 \\
\hline DOI: 10.1159/000488975 & $\begin{array}{l}\text { @ } 2018 \text { The Author(s). Published by S. Karger AG, Basel } \\
\text { www.karger.com/crg }\end{array}$ \\
\hline
\end{tabular}

Simonetto et al:: Autoimmune Ascites Responding to Mycophenolate Mofetil: A Case Report

Table 2. Initial laboratory results (continued)

\begin{tabular}{|c|c|c|}
\hline Test name & Result & Reference \\
\hline \multicolumn{3}{|l|}{ Peritoneal fluid } \\
\hline Removed & $10 \mathrm{~L}$ & \\
\hline Protein & $3.0 \mathrm{~g} / \mathrm{dL}$ & \\
\hline Lactate dehydrogenase & $79 \mathrm{U} / \mathrm{L}$ & \\
\hline Albumin & $2.0 \mathrm{~g} / \mathrm{dL}$ & \\
\hline Amylase & $8 \mathrm{U} / \mathrm{L}$ & \\
\hline Red blood cell count & 38 cells/uL & \\
\hline White blood cell count & 284 cells $/ u L$ & \\
\hline Appearance & clear & \\
\hline Color & yellow & \\
\hline Neutrophils & $5 \%$ & \\
\hline Monocytes & $8 \%$ & \\
\hline Lymphocytes & $87 \%$ & \\
\hline Macrophages & FEW & \\
\hline
\end{tabular}

Overview of the patient's laboratory results during initial presentation in 2013. WBC, white blood cell count; PT, prothrombin time; INR, international normalized ratio; BUN, blood urea nitrogen; AST, aspartate aminotransferase; ALT, alanine aminotransferase; HBsAg, hepatitis B virus surface antigen; HA IgM, hepatitis A immunoglobulin M; Hep C Ab, hepatitis C antibody. 
Table 3. Criteria for POEMS syndrome

Mandatory criteria (both required)

Polyneuropathy

Monoclonal plasma cell proliferative disorder

Major criteria (1 required)

Sclerotic bone lesions

Castleman disease

Elevated levels of vascular endothelial growth factor

Minor criteria (1 required)

Organomegaly

Extravascular volume overload

Endocrinopathy (other than diabetes or hypothyroidism)

Skin changes

Papilledema

Thrombocytosis/polycythemia

Overview of the mandatory, major, and minor criteria required for diagnosing POEMS (polyneuropathy, organomegaly, endocrinopathy, monoclonal protein, skin changes) syndrome. The diagnosis of POEMS syndrome is confirmed when both the mandatory criteria, 1 of the 3 major criteria, and 1 of the 6 minor criteria are present [8]. 